Session 2260

\title{
New Graduate Programs in Petrochemical Technoloy and in Polymer Science at Chulalongkorn University, Bangkok, Thailand --An International Academic Partnership
}

\author{
Raymond D. Daniels, John F. Scamehorn, Somchai Osuwan \\ University of Oklahoma/Chulalongkorn University
}

\begin{abstract}
In 1992, Chulalongkorn University, Bangkok, Thailand, entered into an academic partnership with three U.S. universities (Case Western Reserve University, the University of Michigan, and the University of Oklahoma) to develop and offer graduate programs at the master degree level in petrochemical technology and in polymer science. Students were admitted to the program and the first classes were offered in 1993. The first group of students graduated in July 1995.

The graduate programs as conceived and implemented are international in nature. Instruction is in the English language and curriculum content and thesis requirements are typical of those required in engineering graduate programs at major U. S. universities. Course instructors for the first two years of the program have been faculty from the partnership U.S. universities. Eventually, a near fifty-fifty distribution of U. S. and Thai faculty instruction is anticipated. Thesis research is conducted under U. S. and Thai faculty co-advisors, and the theses are written in English.

The program has received strong support from the government of Thailand and Thai industry. In 1993, the partnership was awarded a USAID, University Development Linkages Project (UDLP) grant. This paper reviews the feasibility studies and planning for these graduate programs and the academic partnership. and it describes our experiences with the program through the first two and one-half years of operation.
\end{abstract}

\section{INTRODUCTION}

\section{Petrochemical Industry in Thailand}

The pace of economic development in Thailand in recent years has been impressive. With manufactured exports growing at 35 to 40 percent per year for five consecutive years., GDP growth in 1994 was 8.5 percent.' Thailand is clearly among the wave of newly industrializing nations. Success, however, has highlighted problems of human resource development and utilization. Key skills in the science and technology fields are in short supply. The underlying reason is the apparent slow response of the educational system to market demand. With reduction in the growth of government employment and the expansion of the industrial sector. there is a change in the skills demanded in the labor market. More engineers, computer scientists, and scientific personnel are required, while there is less demand for the social and political sciences and humanities. A prime example is the human resource requirements of the growing petrochemical industry. 
Thailand is making an extraordinary commitment to develop a sophisticated national petrochemicals industry. The discovery of abundant natural gas reserves in the Gulf of Thailand during the mid 1970's threw open a new era for industrialization and economic development in Thailand, particularly in the oil and gas business. The industry is based on domestic oil reserves of about 1.1 billion barrels and natural gas reserves of about 19 trillion cubic feet. Prior to these discoveries, Thailand was already well along in development of petrochemical downstream plants. producing plastic resins and synthetic fibers from imported monomers and intermediates. With the oil and gas discoveries, the government is determined to maximize the value and utilization of the indigenous natural gas for further development of both upstream and downstream petrochemical industry. An example of this aggressive planning is the monumental Eastern Seaboard Development Program with its new deep-sea port and heavy-industry estate development begun in the 1980's.2

The petrochemical industries in Thailand can absorb all of the chemical engineers the country can supply Because of joint ventures and the heavy participation of multinational companies in the industry, the engineers must be able to work effectively in an international environment. The requirements are straightforward: a master degree level chemical engineer, fluent in the English language, comfortable in plant operations, and an open and participator professional style. These requirements are defined by managers at Thai, foreign. and multinational companies alike. Indeed. many companies operating in Thailand send employees to the United States for the master's degree, often with a bonding obligation.

\section{Chulalongkorn University}

Chulalongkorn University is Thailand's premier university. It was founded in 1916. Today, it has seventeen faculties, two graduate schools, two colleges, twelve research institutes, one language institute, two centers, and three affiliated institutions. Approximately 2,800 teaching staff and 25,000 students occupy a large number of buildings covering its 500 acre campus in the heart of Bangkok. Each year the University graduates about 5,000 students with degrees ranging from bachelor's degrees to doctorates.

Leaders at Chulalongkom University have adopted an aggressive strategy to help build technological infrastructure in Thailand. The initial thrust is directed to the requirements of the petrochemical industries. The University's Petroleum and Petrochemical College was established in 1988 to offer graduate programs and to pursue research, development, and industrial service relevant to the petrochemical and petroleum-based industries. It was obvious then that the nation had to develop technical manpower to serve the fast-growing petrochemical complexes that were coming on stream. The goal for the College was to become a center of excellence in petrochemical and polymer technology, with graduate programs meeting a high international standard. The intent from the outset was for the College to operate as a joint academic endeavor with cooperating universities from the United States. The institutional model was the long-established Sasin Graduate Institute of Business Administration at Chulalongkorn University. That very successful program is a joint academic endeavor with the Kellog Graduate School of Management at Northwestern University and the Wharton School at the University of Pennsylvania.

\section{THE ACADEMIC PARTNERSHIP}

\section{Establishing the Partnership}

In January 1991 the Director of the Petroleum and Petrochemical College visited the United States to assess the range of interest in collaboration with Chulalongkorn University. He visited some 20 university campuses. Among these were Case Western Reserve University, the University of Michigan, and the University 
of Oklahoma. In November 1991, with assistance from the U.S. Agency for International Development (USAID) Mission in Thailand, the University of Oklahoma sent a faculty member to Bangkok to undertake a detailed feasibility study for an academic partnership. In January 1992, faculty members from the Macromolecular Science Department at Case Western Reserve University, the Chemical Engineering Department at the University of Michigan, and the School of Chemical Engineering and Materials Science at the University of Oklahoma. visited Chulalongkorn University for more focused discussions. Representative from the four universities met again in May 1992 at the University of Oklahoma to finalize plans for the academic partnership and the operation of the graduate programs. It was agreed at that time to submit a proposal to USAID for support of the startup of the endeavor through the University Development Linkages Project (UDLP). The UDLP program is intended to facilitate establishment of sustainable linkages between U.S. universities and those in developing countries.

In December 1992 representatives of the three U. S. universities traveled to Bangkok for ceremonies launching the academic partnership with Chulalongkorn University. A Memorandum of Understanding (MOU), setting forth the commitments and obligations of the respective universities to the partnership and signed by all four university presidents, was formally adopted. In May 1993 USAID awarded UDLP finding (\$600,000 over 3 years) for assistance in startup of the collaborative venture. The University of Oklahoma serves as lead institution for the UDLP with the other three universities as linkage partners.

\section{Managing the Partnership}

Chulalongkorn University is responsible for governance of the Petroleum and Petrochemical College, and degrees granted from the College are under the signature of the President of Chulalongkorn University. The College has a Governing Board chaired by the President of Chulalongkorn University. The Board is composed of relevant Thai government officials and representatives from petrochemical and polymer industries. Some of these board members also serve on the Executive Board of the College Chaired by the Director of the College.

The academic partnership is managed by a four-member Steering Committee composed of the Director of the Petroleum and Petrochemical College and department heads at the three U. S. universities (Director, School of Chemical Engineering and Materials Science, University of Oklahoma; Chairman Department of Chemical Engineering, University of Michigan; and Chairman, Department of Macromolecular Science, Case Western Reserve University). The Project Director for the UDLP serves as coordinator for Steering Committee activities and other partnership activities supported by UDLP finds. The Steering Committee is responsible for academic program planning involving the partnership. including setting course and thesis requirements, course selection, and assignment of instructors. Under the MOU, the diplomas of graduates of the Petroleum and Petrochemical college are countersigned by the academic department heads at the three U.S. partner universities.

The first graduate classes in the Petroleum and Petrochemical College were offered in May 1993, with 21 students enrolled in Petrochemical Technology and 18 students in Polymer Science.

\section{THE GRADUATE PROGRAM}

\section{Program Requirements}

Master of Science degree programs are offered in Petrochemical Technology and in Polymer Science. The Petrochemical Technology program is basically a chemical engineering program. All class instruction is conducted in the English language. The degree programs are organized as fill-time, two-year programs. The 
programs include both course work ( 24 credit hours) and thesis research (12 credit hours). Courses ( 3 credit hours each) are offered in four-week modules, Students take only one course at a time. The academic year runs from May to February. Students normally take four to five four-week courses the first year and two to three courses the second year for a minimum of 21 credit hours ( 7 courses), with an additional 2 credits for seminars and 1 credit for an intensive preparatory course. The four-week preparatory course is offered in May at the beginning of the first year. The course is designed to review basic concepts of chemistry and chemical engineering, to provide an overview of the petrochemical and polymer industries and to enhance competency in computers. The course also helps students to develop their skills in the English language and in library research.

Each program consists of core courses and elective courses. There are four core courses in petrochemical technology and five in polymer science. Students are required to take at least three core courses and an additional four courses selected among the remaining core courses and electives. Students in one program are encouraged to take one or two electives from courses offered in the other program. The core courses and the electives offered in the first two years of the program are listed in Table I.

Table I

Course Offerings in Master Degree Programs 1993-95

\begin{tabular}{|c|c|}
\hline Petrochemical Technology & Polymer Science \\
\hline | Core Courses: & | Core Courses: \\
\hline Chemical Reaction Engineering & Introduction to Polymer Science \\
\hline Advanced Chem. Engineering Calculations & I Physical Chemistry of Polymers \\
\hline Advanced Thermodynamics & Polymer Physics \\
\hline Transport Phenomena & I Polymer Synthesis \\
\hline | Elective Courses: & I Polymer Processing \\
\hline Colloid and Surface Science & | Elective Courses: \\
\hline Natural Gas Processing & Polymer Characterization \\
\hline Corrosion Engineering & Inorganic and Organomettalic Polymers \\
\hline Catalysis & Biopolymers with X-Ray Crystallography \\
\hline
\end{tabular}

High quality thesis research is emphasized. Each student is required to complete an acceptable thesis with the anticipation that a high fraction of these theses will result in publication in prestigious international scientific and engineering journals. Students are expected to begin thesis research no later than October or November of their first year. For students entering in May 1993, the deadline for completion of the thesis for graduation in July 1995 was April 1995.

\section{Operation of the Programs}

For the first two years of operation of the graduate program, all curriculum courses have been taught by faculty from the participating U.S. universities. The courses are similar to those offered in graduate programs on 
their home campuses, having the same content, rigor, and expectations. In 1993-94, five courses ( 3 core and 2 elective) were offered in Petrochemical Technology and six (3 core and 3 elective) in Polymer Science. In 199495, five courses were offered in each program ( 3 core and 2 elective in Petrochemical Technology, and 4 core and one elective in Polymer Science). A Thai faculty member is assigned as co-instructor for each course. The course format allows for formal instruction of about 2 to 3 hours in the morning, 5 days per week, for fourweeks. Students have the remainder of the day to work on class assignments and thesis research. Instructors have office hours in the afternoons and sometimes hold informal help sessions for the entire class in the afternoons. Most lectures are video taped and students can review tapes immediately following the lectures. Mid-term and final examinations are required, but more frequent tests can be given, and, often, class projects are assigned. Instructors coming from the U.S. have found the four-week course format quite workable.

There is at least a one-week break between each four-week course. The schedule is heavily front loaded in the academic year, i.e., three courses are offered in the summer months, June, July, and August. At least two additional courses are offered in the period October through January. This scheduling accommodates U. S. faculty who are more readily able to travel during the summer months. It also benefits first year students who are not yet involved in thesis research.

It was originally planned that, beginning in the third year and subsequent years of this program. about one-half of all courses would be taught by Thai faculty However, in 1995-96, only one often courses is being taught exclusively by a Chulalongkom faculty member. Two other courses are being co-taught by U. S. and Thai faculty. The transition to a 50-50 participation in instruction will take place, but more gradually than originally planned.

U.S. faculty participating in the program as instructors are expected to work with Thai faculty and 3-5 graduate students to identify and initiate research projects. A Thai faculty member and a U. S. faculty member are then assigned as co-advisors for each thesis student. The U.S. faculty submit lists of potential research projects for which they are interested in serving as thesis co-advisors. While instructing in Thailand, they present two formal seminars. One is a public seminar for both students and an industry audience. The second is a research seminar for students in which potential research topics are discussed.

Much of the thesis research undertaken in the College in the first two years of the program complements ongoing research programs at the partnership U.S. universities. U.S. faculty benefit from this arrangement by having students work on unfunded research of personal interest and/or to develop preliminary data to include in future research proposals. Thai faculty gain expertise in the thesis research areas being co-advised and, in turn, they share their knowledge of the research challenges specific to Thai industry. These joint efforts enhance the long-term collaboration between Thai and U.S. faculty. Theses completed by students graduating in July 1995 are listed in Tables 11 and III..

\section{Table II \\ Thesis Topics of Students Awarded Master of Science Degree in Petrochemical Technology in 1995}

Gaseous Fuels Storage on Absorbents, Part I: Ethane

Gaseous Fuels Storage on Absorbents, Part II: Butane

Gaseous Fuels Storage on Absorbents, Part III: Propane

Adsolubilization of Styrene and Isoprene in Celtyltrimethyl-Ammonium Bromide Admicelles on Precipitated Silica

Comparison of Rubber Reinforcement Using Various Surface-Modifkd Silicas

Surfactant Adsorption and Soil Decontamination Using Model Soils, Part 1: Negatively Charged Soil Model 
Surfactant Adsorption and Soil Decontamination Using Model Soils, Part II: Positively Charged Soil Model

Surfactant Adsorption and Soil Decontamination Using Model Soils, Part III, Hydrophobic Soil Model

Use of Coacervate to Extract Volatile Organics from Water

Surfactant-Enhanced Carbon Regeneration in Vapor Phase Application

Surfactant Recovery from Water by Foam Fractionation

Surfactant-Enhanced Carbon Regeneration in Liquid Phase Application

Use of Foam Flotation to Remove Tert-Butylphenol from Water

Use of Polyelectrolyte-Enhanced Ultrafiltration (PEUF) to Remove Heavy Metal from Electroplating Wastewater

Precipitation in Solutions Containing Mixtures of Synthetic Anionic Surfactants and Soaps

Monte Carlo Modeling of Heterogeneously Catalyzed Surface Reactions

Catalyst Development for Polyethylene synthesis, Part I: Kinetic Studies

Low-Temperature CO Oxidation by Cobalt Oxide Supported Silver Catalysts

Low-Temperature Total Hydrocarbon Oxidation on Silver/Cobalt Oxide $\left(\mathrm{Ag} / \mathrm{Co}_{3} \mathrm{O}_{4}\right)$ Catalyst

The Flexible Modular Approach in Dynamic Process Simulation

Dynamic Models for Heat Exchangers and Heat Exchanger Networks

\section{Table III \\ Thesis Topics of Students Awarded Master of Science Degrees in Polymer Science in 1995}

Diffusion of Toluene Through HDPE in Toluene-Methanol Mixtures

Catalyst Development for Polyethylene Synthesis, Part II: Characterization

Feasibility of Using Low- Density Polyethylene as Binding Matrix in Glass Fiber Reinforced Plastic Composite

An Experimental Study of Permeation of Representative Gasoline Components through Untreated, Barrier Treated, and Laminated High Density Polyethylene

Phenolic Material via Ring Opening Polymerization of Benzoxazines Copolymerization and Improved Mechanical Properties of Polybenzoxazines

Characterization and Thermal Study of Propargylamine Based Benzoxazine

The Volumetric Expansion of Benzoxazine Based Phenolic Derivatives

Synthesis and Characterization of Phenolphathalein Based Polybenzoxazine

Viscosity Behaviors of Partially Hydrolyzed Polyacrylamides Solutions

A Light Scattering and Viscometric Study on Chain Sizes in Polymethacrylic Acid Solutions

Diffusion Coefficient of Partially Hydrolyzed Polyacrylamides by Dynamic Light Scattering

Viscosity of Polymer Composite at High Shear Rate

Modification of Alumatrane Polymer with Glycerol

Synthesis of Glycolate Silicate Polymer and Property Investigation of its Partial Crosslinking with Glycerol

Polymer Precursor to Spinel Directly from $\mathrm{Al}(\mathrm{OH})_{3}, \mathrm{MgO}$, and TEA, and its Modification with Glycerol

Synthesis of Alumatrane Oligomers

Synthesis of Siltrane Complex Directly from Silica and TEA

Aryloxysilane Synthesis Directly from Silica

\section{Faculty and Student Exchange Visits}

Important features of the startup program supported by UDLP are the provisions for faculty and student exchange visits. In first two years of the program there have been visits by ten Chulalongkorn faculty to U. S. partner universities. Some visits have been as short as two weeks and some as long as three months. The goal of these visits is to identify collaborative research opportunities and to help build personal, professional and institutional bonds. Visits to Chulalongkom University by U. S. university faculty are accomplished through the instructional programs at the College and via teaching College-sponsored short courses to Thai industry .

Student exchanges have also occurred. In fact, $\mathbf{3 7}$ of the $\mathbf{3 9}$ students in the first graduating class at the Petroleum and Petrochemical College had the opportunity to perform some of their research work at the U.S. universities. All but three students received support for their travel from the UDLP. These three students 
received finding from their U.S. thesis advisor. A number of students performed laboratory work while in the U.S. This was necessary because some needed laboratory equipment was not yet available at the Petroleum and Petrochemical College. Other students, having completed laboratory work. came to use the university libraries and visit with their U.S. faculty advisors in preparing the thesis. These visits averaged about a four to six weeks in duration, but several were much longer.

Four graduate students from the partner U.S. universities visited Chulalongkorn University in 1994-95. These students were doctoral candidates, with experience as research assistants. They assisted Chulalongkorn students with their thesis research projects, particularly in learning specialized procedures used in research at the U.S. universities. Exposure of U. S. students to Thai culture is another important benefit of the linkage. These visits to Thailand averaged about one month in duration.

\section{Physical Facilities and Equipment}

The Petroleum and Petrochemical College occupies eight floors of a 14-story building situated on the north edge of the Chulalongkorn University Campus. The building is new, completed in 1993. Classes were underway in May 1993 even before construction was entirely complete. The 7,000 square meter floor area houses administrative offices, classrooms, seminar and conference rooms of various sizes, six laboratories, a computer center, a library, an instrumentation center, and an industrial service center. Staffing of the College (as of July 1995) consists of thirteen fill-time Thai faculty members. supported by three expatriate experts, eight researchers, and four technicians. There are about twenty administrative support staff.

The College received a grant of 160 million baht (US \$6.4 million) from the Royal Thai Government in 1992. The finds are being received over a period of five years. More than $\mathbf{7 5}$ percent of the funds have now been expended. As a result, the College laboratories are already among the best equipped in Thailand.

Although much general purpose laboratory equipment was already in place in 1993, some of the specialized instrumentation needed in specific thesis research areas was not available. This posed problems for the first class of students, since the procurement process for equipment, especially highly specialized and expensive equipment, involves rather long lead times. Some students came to the U.S. specifically to use equipment not yet available at the College. These equipment deficiencies are gradually being overcome, and succeeding classes will work in laboratories well-equipped for the research being undertaken. The equipment is new and state-of-the-art. In the future, U.S. graduate students may travel to Thailand to use instrumentation unavailable in their U.S. laboratories.

Computing and library resources have been slow to develop. It took about a year to install a computer network adequate for the instructional and research needs of the College. One important factor is internet access. This is the major mode of communication between students and their U. S. faculty advisors. It took some months before students were able to obtain unrestricted access to terminals linked to the intemet. Without e-mail and fax it is doubtful that this partnership could be workable.

The problem of inadequate library resources at the College may never be completely solved. The College has purchased many books recommended by U. S. faculty and is reasonably well positioned in books in areas of active research. Literature search resources, such as Chemical Abstracts, are available. Journal articles are the most significant problem. To help in specific research areas, faculty have provided the library with files of significant research papers. As journals become available on-line, this limitation will be lessened. 


\section{Program Costs and Funding}

The graduate programs of the College have a high tuition by Thai standards. The tuition for each student for an academic year is 200,000 baht (US \$8,000). This is significantly more than tuition in most other programs at Chulalongkom University. Scholarships offset much of the tuition costs for the class that entered in 1993. Of the 39 students in the class, 36 received tuition scholarships. Twenty of the scholarships were provided by the Petroleum Authority of Thailand. Of the 35 students entering in 1994,21 received scholarships. Of the 36 students entering in 1995, 20 received scholarships. Although the number of scholarships available has decreased from the first year, there is a continued steady supply of well-qualified applicants for enrollment with more and more applicants expressing willingness to pay their own tuition. This clearly indicates that the graduate programs are receiving very affirmative recognition.

Tuition income is sufficient to cover direct costs of instruction, which include stipends and travel expenses for U.S. faculty and salary supplements for participating Thai faculty. Tuition also provides a basic allowance for research expenses of each student. Chulalongkorn University provides support for College administration and faculty salaries. The University also helps to fund some of the students' research work.

Engineering research programs are expensive. To support a quality engineering graduate program with thesis requirements, the College is actively building a substantial level of continuing, externally-funded research projects. Additional sources of revenue are continuing education, and an industrial testing and services. Progress is underway in developing all of these activities.

Continuing education renders an important service to industry. It also helps to focus public attention on the programs and resources of the College, and it can provide a significant revenue stream. Short courses and workshops for industry were initiated in 1993 utilizing some of the visiting U.S. faculty. Two courses were offered in 1993 and six more in 1994. Twelve courses were offered in 1995, now using both visiting and inhouse instructors.

Research grants and contracts as we know them in the U.S. have been slow to develop, but significant progress is being made in the College. The Thai Government funds some research on a competitive basis. In 1995 , the College faculty received four grants totaling 701,400 baht (US $\$ 28,000$ ). Five more projects were approved for 1996, totaling 1,096,900 baht $(\$ 44,000)$.

The National Research Council of Thailand funds student research projects on a competitive basis. In 1994, seventeen students in the College received 30,000 baht each to support their research. Student proposals submitted in 1995 are still pending.

Industrial contacts and visits to industrial sites are a high priority in the College. Industry visits are arranged for U.S. faculty while in Thailand. Several research projects sponsored by industry are in the works, but more are needed. The situation will improve as the College earns credibility through the quality of its graduates and its current research activities.

An industrial Services Laboratory was established to make the specialized equipment and instrumentation in the College available to industry for testing and process development. Examples of services being performed include: analysis of waste water and solid waste, analysis and testing of petroleum products, analysis of industrial chemicals, and testing of polymer and plastics products. The College recently signed a memorandum of understanding with the Federation of Thai Industries to establish a Plastic Technology Service Center. The 
center will provide consultation, training, testing services, and basic research services to the plastics products industry.

\section{Profile of Students}

The graduate programs have attracted top students from a number of universities in Thailand and also some graduates already at work in industry. The average GPA of students accepted in each class has been well above 3.0. In the class entering in 1993, 29 of the 39 students are graduates of Chulalongkorn University, with degrees in chemical engineering, chemistry, or materials science. As information about the graduate programs has spread throughout Thailand. the number of students from other universities has increased. In the class entering in 1994, 19 of35 students are Chulalongkorn graduates. In 1995, only 15 of 36 new enrollees are Chulalongkorn graduates. Graduates of eleven other universities in Thailand and one foreign university are represented in the class entering in 1995. The College is encouraging applications for admission from students outside Thailand. There is one overseas student in each of the first three classes.

The College graduated its first class of students in July 1995 with21 in the Petrochemical Technology program and 18 in the Polymer Science program. Almost all of the students found employment in Thai industry within a month of graduation. Several are continuing their studies in Ph.D. programs at the U.S. partner universities. With the continued growth of the Thai petrochemical industry, job opportunities for succeeding classes are expected to as good as, if not better than, those for the first class.

\section{A LOOK TO THE FUTURE}

\section{Sustaining the Collaborative Venture}

In establishing the academic partnership, the participating universities set a common goal . . to test, authenticate, and promote new models for international technological collaboration through establishment of a center of international engineering excellence (i.e., education, research and industrial service) in Thailand.

Most important to the accomplishment of this goal is sustainability of the collaborative venture. Factors contributing to sustainability are the development of personal, professional, and institutional bonds. On a personal level it is necessary to develop friendships among the persons involved. On a professional level it is necessary to develop collaborations in research and pedagogy. On an institutional level it is necessary that the academic partnership be recognized and supported at the highest administrative levels of the universities involved. The partnership is meeting the test in all three areas.

Increased research productivity for the U.S. faculty participating in the collaboration justify continued involvement of the U. S. university partners. The collaboration also advances the strategic objective of the U. S universities for greater global reach.

\section{Funding Outlook}

The collaboration must also be cost effective for the universities involved. The UDLP finding ends in 1996. Program-generated funds must pick up the costs of activities currently funded by the UDLP. These costs are primarily travel expenses for meetings and personnel exchanges. We believe this will be accomplished through continued growth of sponsored research and the programs of continuing education and industrial services. 
Thai industry can see the direct value of the collaboration as they employ graduates, use research and testing facilities in the College, and attend short courses taught by recognized experts. Establishing the credibility of the program will also enhance the ability of the College to obtain finding from private foundations and Thai government agencies. Given the healthy state of the petrochemical industry in Thailand, there is a great opportunity for building these relationships and establishing a stable finding base for the program long-term.

\section{Expanding the Collaboration}

Plans are underway to begin to offer Doctor of Philosophy degree programs in the College. This is in line with the need to develop continuity for long-term research projects. The general operation of the programs will be similar to the master degree programs. Students will complete most of the required course work under the current program. Dissertation research will be carried our under the co-supervision of U. S. and Thai faculty.

\section{REFERENCES}

1. Hydrocarbon Asia, July/August 1995, pp 16-24

2. Overview, Thailand's Eastern Seaboard Development Program, Office of the National Economic and Social Development Board, June 1992

\section{BIOGRAPHICAL INFORMATION}

Raymond D. Daniels is Professor Emeritus of Chemical Engineering and Materials Science at the University of Oklahoma. He received BS and MS degrees in physics and PhD in metallurgy from Case Institute of Technology (Case Western Reserve University). He served on the faculty at the University of Oklahoma for $\mathbf{3 6}$ years, receiving an emeritus appointment in 1993. He was the initial project director for the USAID UDLP.

John F. Scamehorn is Asahi Glass Chair and George Lynn Cross Research Professor of Chemical Engineering and Materials Science at the University of Oklahoma. He received BS and MS degrees in chemical engineering from the University of Nebraska and PhD from the University of Texas at Austin. He is the current project director for the USAID UDLP.

Somchai Osuwan is Professor of Chemical Engineering and Director of the Petroleum and Petrochemical College at Chulalongkorn University. He received the BS degree at Chulalongkom and MS and PhD degrees in chemical engineering from the University of New Brunswick. 